\title{
Functional aspects of recollective experience
}

\author{
JOHN M. GARDINER \\ The City University, London, England
}

\begin{abstract}
The functional relationship between recognition memory and conscious awareness was examined in two experiments in which subjects indicated when recognizing a word whether or not they could consciously recollect its prior occurrence in the study list. Both levels of processing and generation effects were found to occur only for recognition accompanied by conscious recollection. Recognition in the absence of conscious recollection, although less likely, was generally reliable and uninfluenced by encoding conditions. These results are consistent with dual-process theories of recognition, which assume that recognition and priming in implicit memory have a common component. And they strengthen the case for making a functional distinction between episodic memory and other memory systems.
\end{abstract}

The function of conscious awareness in memory has gained a fresh importance in contemporary memory research. This importance stems largely from two related sets of findings: neuropsychological findings from studies with amnesic patients and findings of related patterns of functional dissociation from studies with memoryunimpaired adults. Both sets of findings can be described in terms of the distinction that has been made between explicit and implicit memory tests (Graf \& Schacter, 1985; see Schacter, 1987, for a recent review). Explicit memory tests are those in which subjects are asked to remember, in the sense of being able consciously to recollect, prior events and experiences. Such tests include conventional episodic memory tests such as recognition and recall. Implicit memory tests are those in which the conscious recollection of prior events and experiences is not required. Such tests include perceptual identification, lexical decision, and word-stem and word-fragment completion. The priming effects observed in these implicit memory tests (superior performance on items that have been previously encountered in the experiment) are the hub of both related sets of findings. Despite their very poor performance in explicit memory tests, amnesic patients have often been found to exhibit normal or nearnormal priming effects, and, in memory-unimpaired adults, priming effects typically have been found either to be uninfluenced by variables, such as levels of processing, that have large effects in explicit memory, or to be influenced in opposite ways by such variables. Unquestionably, therefore, there are fundamental differences in the nature of the memory observed in tests of explicit and implicit memory, and the function of conscious awareness is pivotally important to these differences.

I am grateful to Endel Tulving for helpful discussion, and to Rosalind Java and Gerard Whittaker for their help with data collection and analysis. Address reprint requests to John M. Gardiner, Memory \& Cognition Research Group, The City University, Northampton Square, London ECIV OHB, England.
Memory theorists have advocated two alternative conceptualizations of the differences between explicit and implicit memory. Some theorists have proposed that these differences reflect the operation of functionally distinct memory systems. One such proposal distinguishes between procedural and declarative memory (Squire, 1982; Squire \& Cohen, 1984). Another distinguishes between three memory systems-procedural, semantic, and episodic memory (Tulving, 1983, 1985a). According to these theories, the neuropsychological findings are interpreted as evidence that the amnesic syndrome is selective in that it damages particular memory systems and spares others. Similarly, functional dissociations between explicit and implicit memory performance in memory-unimpaired adults are interpreted as evidence that different memory systems are tapped by the two sorts of test.

Other theorists have argued against a memory systems approach and have proposed instead that the differences between explicit and implicit memory performance are more appropriately conceptualized in terms of a process analysis that is based on a more unitary view of memory representation. These theorists typically distinguish between two sorts of processing, or kinds of encoded information, such as between conceptually driven and datadriven processing (Jacoby, 1983; Roediger \& Blaxton, 1987) or between the elaboration and integration of stimulus information (Graf \& Mandler, 1984; Mandler, 1980). According to these theories, the neuropsychological findings are interpreted as evidence that memory is impaired with respect to one sort of processing (or kind of information) and that the other sort of processing remains relatively intact. Similarly, functional dissociations between explicit and implicit memory performance in memoryunimpaired adults are interpreted as evidence that different sorts of processing are more or less appropriate for the different types of test. Furthermore, on the strength of findings that certain variables also have parallel effects on recognition memory performance and on priming (e.g., Jacoby \& Dallas, 1981), theorists of this persuasion have argued additionally that recognition and priming have a 
component in common, and that recognition therefore entails both sorts of processing (but see Squire, Shimamura, \& Graf, 1985; Watkins \& Gibson, in press).

The purpose of the present article is to describe some findings that are of interest in relation to these issues and that involve a different empirical approach. This approach makes use of a technique suggested by Tulving (1985b) for measuring, rather than manipulating, the nature of subjects' conscious awareness during the memory test. Tulving (1985b) described two experiments in which he required subjects to put an " $R$," for "remember," next to items in the test whose prior occurrence in the study list they could consciously recollect and a " $\mathrm{K}$," for " know," next to items they recalled or recognized on some other basis. One experiment showed that the proportion of "remember"' responses decreased systematically from uncued through cued recall. Another, recognition memory, experiment showed that the proportion of "remember" responses decreased over a 1-week retention interval and that it was positively correlated with subjects' rated confidence in the accuracy of their responses. These demonstrations show that subjects can make meaningful judgments about their conscious experience in memory tests. They also support Tulving's (1983, $1985 \mathrm{a}, 1985 \mathrm{~b}$ ) conception of retrieval as a joint product of encoding and retrieval information, which in turn gives rise to feelings of conscious recollection.

In contrast to Tulving's (1985b) emphasis on retrieval factors, the focus of the present article is on the influence of encoding factors on subjects' conscious experience. More particularly, the purpose of this study was to determine the functional relationship between two wellknown episodic memory phenomena-levels of processing and generation effects-and conscious experience in recognition memory.

No very strong grounds seem to exist for predicting a particular form for this relationship, and at least some possible relationships would not be of much interest. For example, one relatively uninteresting, but quite plausible, possibility is that "remember" and "know" responses might similarly be influenced by encoding conditions, but with "know" responses being generally less likely. This outcome would be expected if "remember" and "know" measures were merely equivalent to confidence ratings, because there is evidence that such encoding conditions affect recognition of words for which subjects give low confidence ratings, as well as words for which they give high confidence ratings (see, e.g., Slamecka \& Graf, 1978). Also, this outcome could all too readily be interpreted in terms of the simple notion that "remember" and "know" responses reflect nothing more or other than strong and weak memory traces.

Tulving's (1983, 1985a, 1985b) proposal of separate procedural, semantic, and episodic memory systems suggests a more interesting possibility. According to this proposal, different kinds of conscious awareness are postulated for each system and recollective experience is a defining property of episodic memory, which implies that there should be an essentially perfect correlation be- tween recollective experience and such episodic memory phenomena as levels of processing and generation effects. In this eventuality, recognition memory in the absence of conscious recollection may be linked with priming effects in implicit memory tests, and the overall results would be consistent with dual-process theories of recognition that maintain that recognition and priming have a common component.

\section{EXPERIMENT 1}

In Experiment 1, encoding conditions were manipulated by giving the subjects incidental learning instructions and orienting tasks that involved encoding either at a phonemic or at a semantic level. Following many previous demonstrations of levels of processing effects (see, e.g., Craik \& Tulving, 1975), recognition memory performance was expected to be superior after the semantic orienting task. The subjects were instructed in the test that when recognizing a word they were to indicate whether they were able consciously to recollect its prior occurrence in the study list ("remember") or whether they recognized it on some other basis ("know'). The point of the experiment was to relate the levels of processing effect to the nature of subjects' conscious awareness in the recognition test.

\section{Method}

Subjects. The subjects were 32 undergraduates at The City University, London; most were students in an introductory laboratory course. They were tested in small groups, they participated in the experiment without pay, and they were allocated arbitrarily to one of the two between-subjects conditions.

Design. All subjects were presented with a list of 36 words; 16 subjects had to produce a semantic associate for each word, and 16 subjects had to produce a rhyming word. The subjects were told that these tasks were for the collection of normative free association data. One hour later the subjects were given a recognition test consisting of the 36 words from the study list together with 36 lure words. They were required to circle words they recognized from the study list and indicate whether or not their recognition was accompanied by conscious recollection. Target words and lure words were yoked across groups, and within each group target words for half the subjects were lure words for the other half.

Procedure. The 72 words used in the experiment were all common one-syllable or two-syllable nouns. They were divided arbitrarily into two sets of 36 for use as target words and lure words. Study lists were presented in booklets with one word per page. For one group of subjects, the first page of the booklet consisted of instructions to write down next to each word the first word that came to mind that rhymed with the given word, or a word that sounded very much like it. For the other group of subjects, the instructions were to write down next to each word the first word that came to mind that was semantically or meaningfully related to the given word. The subjects were told that the tasks were typical free association tasks used for collecting normative data. The orienting tasks were self-paced, but no systematic difference in their duration was observed; subjects typically took about $5 \mathrm{sec} / \mathrm{item}$. There was then a 1-h retention interval during which subjects attended a practical class.

The order of words in the study list was randomized separately for each subject, but the words in the recognition test were presented in a single constant order, typed in three columns of 24 words each. In this test the subjects were told to work carefully down each 
column in turn, drawing a circle around each word that they recognized from the study list. In addition, the test was immediately preceded by instructions explaining that at the time they recognized each word, they were also to write an " $R$," for "remember," if their recognition of the word was accompanied by a conscious recollection of its prior occurrence in the study booklet or a " $\mathrm{K}$," for "know," if they did not consciously recollect the word's occurrence in the study booklet but recognized it on some other basis. "Remember" was defined in these instructions as the ability to become consciously aware again of some aspect or aspects of what happened or what was experienced at the time the word was presented (e.g., aspects of the physical appearance of the word, or of something that happened in the room, or of what one was thinking or doing at that time). "Know" responses were defined as the recognition that the word was in the booklet but the inability to recollect consciously anything about its actual occurrence or what happened or what was experienced at the time of its occurrence. To further illustrate this distinction, the instructions pointed out that if asked one's own name, one would typically respond in the "know" sense, that is, without becoming consciously aware of anything about a particular event or experience; however, when asked what movie one saw last, one would typically respond in the "remember" sense, that is, becoming consciously aware again of some aspects of the particular experience. One subject failed to write any " $R$ " and " $K$ " responses in the test, and this subject was replaced

\section{Results}

The data were analyzed separately in terms of the probability of "remember" and "know" responses for correct recognition judgments and for false positive errors (i.e., in each case the overall mean probability of making a recognition judgment is the sum of the separate mean probabilities of "remember" and "know" responses). These data are summarized in Figure 1. As Figure 1 shows, there was a strong levels of processing effect, but this effect occurred only for words whose recognition was accompanied by conscious recollection. Recognition in the absence of such recollective experience was less likely, but far from negligible, and it was quite uninfluenced by level of processing. These observations are supported by the results of an analysis of variance (ANOVA) carried out on individual subjects' correct recognition scores, with levels of processing and response type as factors. 'Both the main effect of levels $[F(1,30)=16.74, p<.001$, $M S \mathrm{e}=.01]$ and that of response type $[F(1,30)=92.97$, $p<.001]$ were significant, as was the interaction between them $[F(1,30)=5.02, p<.05, M S e=.03$ in each case]. The extremely low false positive rates

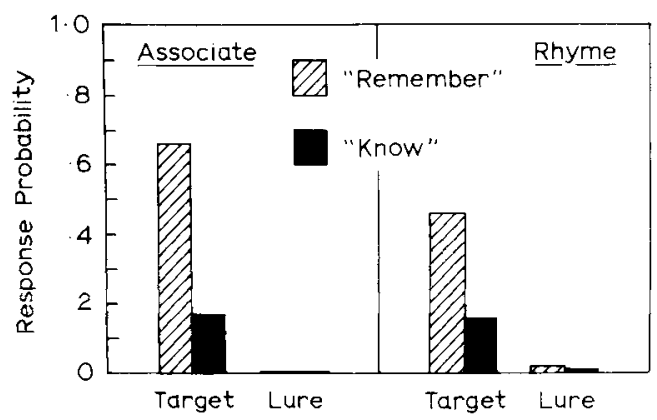

Figure 1. Response probability as a function of levels of processing. precluded any statistical analyses of those data, but in both the associate group and in the rhyme group 14 of 16 subjects made more "know" responses to target words than they did to lure words ( $p<.001$ by sign test), with two ties in each case.

\section{EXPERIMENT 2}

In Experiment 2, encoding conditions were manipulated by giving subjects a list of words, half of which had to be generated in the context of a given rule and half of which had to be read. Following many previous demonstrations of generation effects (see e.g., Slamecka \& Graf, 1978), recognition memory performance was expected to be superior after the generate task. The subjects were given instructions in the test that were similar to those given in Experiment 1. The point of the experiment was to relate the generation effect to the nature of the subjects' conscious awareness in the test. In addition, however, Experiment 2 was designed to provide further information about the effects of retention interval, so recognition tests were given at two retention intervals, $1 \mathrm{~h}$ and 1 week, with a different group of subjects assigned to each retention interval.

\section{Method}

Subjects. The subjects were 40 undergraduate students at The City University, London, who were allocated arbitrarily into one of two equal groups, tested individually, and were paid for their participation in the experiment.

Design. All subjects studied a list of 24 common pairs of opposites, 12 of which were generated and 12 read. Half the subjects were given a recognition test $1 \mathrm{~h}$ later, and half were given the test 1 week later. In the test, the 24 target words were mixed with 24 lure words, and the subjects were required to indicate whether or not each recognition judgment was accompanied by conscious recollection. Within each retention interval group, the 48 words used in the experiment were fully rotated across presentation and test conditions.

Procedure. A set of 48 common pairs of opposites was compiled, with one member of the pair designated the stimulus, the other the response. The pairs were selected on the basis of pretrials, which indicated that given the stimulus and the first letter of the response, successful generation of the designated target was guaranteed. The 48 pairs were arbitrarily split into two sets of 24 for use as the alternate study lists. Half the subjects in each group studied one list, half the other. Within each list, but across subjects, each word pair was used equally often in generate and read conditions. Each word pair was printed on a separate card. In the generate condition only the first letter of the target word was printed; in the read condition the target word was printed in full. The cards were presented at a 5-sec rate, and the subjects were told the "rule" was opposites and were instructed to say aloud the response words in each case, whether generated or read, and to study them for a subsequent memory test, the nature of which was not specified. A separate random order of items within the list was used for each subject.

The recognition test consisted of all 48 response words, arranged in a constant random order of three columns with 16 words in each. The tests were given 1 h or 1 week after the study session. Some of the subjects in the 1-h group attended a lecture during that time, but for the most part the retention interval was unfilled. The test instructions given were similar to those given in Experiment 1. Two subjects in the l-week retention interval group failed to comply with 
the instructions, and data from these subjects were excluded from analysis; to balance the numbers, data from two corresponding subjects in the 1-h retention interval group were also excluded.

\section{Results}

The data were analyzed in the same manner as in Experiment 1 and are summarized in Figure 2. As Figure 2 shows, there were large generation effects, and these effects occurred only for words whose recognition was accompanied by conscious recollection of their prior occurrence in the study list. The generation effect seems attenuated but still present after a 1-week retention inter$\mathrm{val}$, and the decline in recognition performance after a 1-week interval, like the generation effect itself, seems similarly confined to words whose recognition was accompanied by recollective experience. False positive rates were somewhat greater in Experiment 2 than in Experiment 1 , and after 1 week increased somewhat, especially for recognition judgments made in the absence of recollective experience: for these "know" responses, there was little apparent difference between false positive and hit rates.

The foregoing observations are supported by the results of an ANOVA carried out on individual subjects' correct recognition scores, with generate versus read conditions, retention interval, and response type as factors. All main effects were significant: $F(1,34)=35.23, p<.001, M S$ e $=.01$, for the generation effect; $F(1,34)=6.35$, $p<.05, M S \mathrm{e}=.03$, for retention interval; and $F(1,34)$ $=39.63, p<.001, M S e=.06$, for response type. The interaction between encoding conditions and response type was significant $[F(1,34)=29.47, p<.001, M S e=.02]$, as were those between response type and retention interval $[F(1,34)=6.90, p<.05, M S \mathrm{e}=.06]$ and between encoding conditions and retention interval $[F(1,34)=$ $7.10, p<.05, M S e=.01]$. The three-way interaction was not significant $[F(1,39)=2.06, M S e=.02]$.

The results of a comparable ANOVA on false positive responses showed only a significant effect of retention interval $[F(1,34)=19.38, p<.001, M S e=.01]$, with $F<1$ for the main effect of response type, and $F(1,34)$ $=2.66$ for the interaction between response type and retention interval ( $M S \mathrm{e}=.01$ in each case). At the 1week retention interval, only 9 of 16 subjects made more

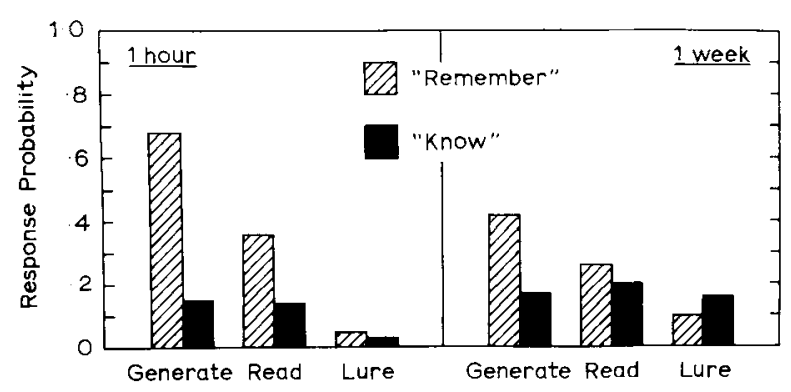

Figure 2. Response probability as a function of generate versus read conditions and retention interval. "know" responses to target words than they did to lure words; there were two ties. At the 1-h retention interval, 15 of 16 subjects made more "know" responses to target words than they did to lure words, again with two ties ( $p<.001$ by sign test). After 1 week, therefore, in contrast with $1 \mathrm{~h}$, subjects were unable in the absence of conscious recollection reliably to distinguish target words from lures.

\section{GENERAL DISCUSSION}

Both levels of processing and generation effects were found to occur only for words whose recognition was accompanied by conscious recollection. Recognition in the absence of recollective experience, although less likely, was generally reliable, and it was completely uninfluenced by encoding conditions. The clear-cut nature of this dissociation argues against the possibility that "remember" and "know" responses simply reflect strong and weak traces, for even weak traces should be influenced to some extent by encoding conditions. Rather, it suggests some correspondence with functional dissociations previously observed in studies that have manipulated conscious awareness by comparing performance in explicit and in implicit memory tests (see Schacter, 1987). Of additional interest in this connection is the finding in Experiment 2 that recognition memory in the absence of conscious recollection does not appear to persist for as long as a week. $^{2}$

More particularly, the overall results are consistent with the assumption that recognition memory may entail two processes, one of which may also give rise to priming effects in implicit memory tests (see, e.g., Graf \& Mandler, 1984; Jacoby \& Dallas, 1981; Mandler, 1980). The "implicit" component is assumed by these theorists to reflect data-driven, rather than conceptually driven, processing, or stimulus integration rather than elaboration, and to be dependent mainly on prior exposure to the stimulus. Speculatively, the results suggest that "know" responses may be a relatively pure measure of this component, whereas "remember" responses may be primarily a measure of the "explicit" component, which reflects conceptual or elaborative processing. If this is so, it should be possible to establish further, convergent links between these measures and the two sorts of processing.

From the standpoint of Tulving's $(1983,1985 \mathrm{a}, 1985 \mathrm{~b})$ distinction between procedural, semantic, and episodic memory systems, conscious recollection is a defining property of episodic memory. The case for making a functional distinction between episodic memory and other memory systems is therefore materially strengthened by evidence that such staple episodic memory phenomena as levels of processing and generation effects are indeed truly episodic, as defined and measured by the nature of subjects' conscious awareness. "Know" responses, by this account, may reflect semantic memory priming or even, perhaps, a form of procedural memory. If this is so, it 
should be possible to use these measures to examine directly the interface between episodic and other memory systems.

Thus it seems that these measures of consciousness in memory may usefully supplement our understanding of explicit and implicit memory performance. It is also quite possible, however, that there may turn out to be a more optimal way of measuring explicit and implicit components of conscious awareness, and some priority in future research should be given to further elucidating the nature of the measures per se. Further evidence on the relation between these measures and confidence ratings would, for example, clearly be desirable. So, too, would evidence about whether there is any necessary correlation between the proportion of "remember" and "know" responses and level of performance. For the moment, these matters, and other related issues that might well be raised, are left unresolved. But at least the present studytogether with that of Tulving (1985b)-seems to offer a promising beginning.

\section{REFERENCES}

Craik, F. I. M., \& Tulving, E. (1975). Depth of processing and the retention of words in episodic memory. Journal of Experimental Psychology: General, 104, 268-294.

Graf, P., \& MANDler, G. (1984). Activation makes words more accessible, but not necessarily more retrievable. Journal of Verbal Learning \& Verbal Behavior, 23, 553-568.

Graf, P., Schacter, D. L. (1985). Implicit and explicit memory for new associations in normal and amnesic subjects. Journal of Experimental Psychology: Leaming, Memory, \& Cognition, 11, 501-518.

JACOBY, L. L. (1983). Remembering the data: Analyzing interactive processes in reading. Journal of Verbal Learning \& Verbal Behavior, 22, 485-508.

JACOBY, L. L., \& DALlAS, M. (1981). On the relationship between autobiographical memory and perceptual learning. Joumal of Experimental Psychology: General, 3, 306-340.

MANDLER, G. (1980). Recognizing: The judgment of previous occurrence. Psychological Review, 87, 252-271.

Roediger, H. L., III., \& Blaxton, T. A. (1987). Retrieval modes produce dissociations in memory for surface information. In D. S. Gorfein \& R. R. Hoffman (Eds.), Memory and cognitive processes: The Ebbinghaus Centennial Conference (pp. 349-379). Hillsdale, NJ: Erlbaum.

SCHACTER, D. L. (1987). Implicit memory: History and current status. Journal of Experimental Psychology: Learning, Memory, \& Cognition, 13, 501-518.

Slamecka, N. J., \& Graf, P. (1978). The generation effect: Delineation of a phenomenon. Journal of Experimental Psychology: Human Learning \& Memory, 4, 592-604.

SQuire, L. R. (1982). The neuropsychology of human memory. Annual Review of Neuroscience, 5, 241-273.

SQuire, L. R., \& CoHEN, N. J. (1984). Human memory and amnesia In G. Lynch, J. L. McGaugh, \& N. M. Weinberger (Eds.), Neurobiology of memory (pp. 3-64). New York: Guilford Press.

Squire, L. R., Shimamura, A. P., \& Graf, P. (1985). Independence of recognition memory and priming effects: A neuropsychological analysis. Joumal of Experimental Psychology: Learning, Memory, \& Cognition, 11, 37-44.

Tulving, E. (1983). Elements of episodic memory. New York: Oxford University Press.

Tulving, E. (1985a). How many memory systems are there? American Psychologist, 40, 385-398.

Tulving, E. (1985b). Memory and consciousness. Canadian Psychologist, 26, 1-12.

Watkins, M. J., \& Gibson, J. M. (in press). On the relation between perceptual priming and recognition memory. Journal of Experimental Psychology: Learning, Memory, \& Cognition.

\section{NOTES}

1. The treatment of response type as an independent variable in this analysis is questionable, and perhaps this factor is more properly regarded as a dependent variable. On the other hand, one might suggest that the analysis is not unreasonable, even if its legitimacy is somewhat questionable, and it seems unlikely that any alternative statistical approach would lead to very different conclusions about the pattern of results observed.

2. It is intriguing that this finding is associated with an increase in the proportion of "know" responses to lures, but it is not easy to see what this might signify.

(Manuscript received June 4, 1987; revision accepted for publication December 16, 1987.) 